\title{
Metallic nickel nano- and fine particles induce JB6 cell apoptosis through a caspase-8/AIF mediated cytochrome c-independent pathway
}

\author{
Jinshun Zhao', Linda Bowman ${ }^{1}$, Xingdong Zhang1, Xianglin Shi², \\ Binghua Jiang ${ }^{3}$, Vincent Castranova ${ }^{1}$ and Min Ding*1
}

Address: ${ }^{1}$ Pathology and Physiology Research Branch, Health Effects Laboratory Division, National Institute for Occupational Safety and Health, Morgantown, WV, 26505, USA, ${ }^{2}$ Graduate Center for Toxicology, College of Medicine, the University of Kentucky, Lexington, KY, 40515, USA and ${ }^{3}$ Department of Microbiology, Immunology, and Cell Biology, West Virginia University, Morgantown, WV, 26505, USA

Email: Jinshun Zhao - fyq9@cdc.gov; Linda Bowman - llb2@cdc.gov; Xingdong Zhang - xaz5@cdc.gov; Xianglin Shi - xshi5@email.uky.edu; Binghua Jiang - bhjiang@hsc.wvu.edu; Vincent Castranova - vic1@cdc.gov; Min Ding* - mid5@cdc.gov

* Corresponding author

\section{Published: 20 April 2009}

Journal of Nanobiotechnology 2009, 7:2 doi:10.1186/1477-3155-7-2
Received: 21 January 2009

Accepted: 20 April 2009

This article is available from: http://www.jnanobiotechnology.com/content/7/I/2

(c) 2009 Zhao et al; licensee BioMed Central Ltd.

This is an Open Access article distributed under the terms of the Creative Commons Attribution License (http://creativecommons.org/licenses/by/2.0), which permits unrestricted use, distribution, and reproduction in any medium, provided the original work is properly cited.

\begin{abstract}
Background: Carcinogenicity of nickel compounds has been well documented. However, the carcinogenic effect of metallic nickel is still unclear. The present study investigates metallic nickel nano- and fine particle-induced apoptosis and the signal pathways involved in this process in JB6 cells. The data obtained from this study will be of benefit for elucidating the pathological and carcinogenic potential of metallic nickel particles.

Results: Using 3-(4,5-dimethylthiazol-2-yl)-2,5-diphenyltetrazolium bromide (MTT) assay, we found that metallic nickel nanoparticles exhibited higher cytotoxicity than fine particles. Both metallic nickel nano- and fine particles induced JB6 cell apoptosis. Metallic nickel nanoparticles produced higher apoptotic induction than fine particles. Western-blot analysis showed an activation of proapoptotic factors including Fas (CD95), Fas-associated protein with death domain (FADD), caspase-8, death receptor 3 (DR3) and BID in apoptotic cells induced by metallic nickel particles. Immunoprecipitation (IP) western blot analysis demonstrated the formation of the Fas-related death-inducing signaling complex (DISC) in the apoptotic process. Furthermore, lamin A and beta-actin were cleaved. Moreover, we found that apoptosis-inducing factor (AIF) was up-regulated and released from mitochondria to cytoplasm. Interestingly, although an up-regulation of cytochrome $c$ was detected in the mitochondria of metallic nickel particle-treated cells, no cytochrome $c$ release from mitochondria to cytoplasm was found. In addition, activation of antiapoptotic factors including phospho-Akt (protein kinase B) and Bcl-2 was detected. Further studies demonstrated that metallic nickel particles caused no significant changes in the mitochondrial membrane permeability after $24 \mathrm{~h}$ treatment.
\end{abstract}

Conclusion: In this study, metallic nickel nanoparticles caused higher cytotoxicity and apoptotic induction than fine particles in JB6 cells. Apoptotic cell death induced by metallic nickel particles in JB6 cells is through a caspase8/AIF mediated cytochrome c-independent pathway. Lamin A and beta-actin are involved in the process of apoptosis. Activation of Akt and Bcl-2 may play an important role in preventing cytochrome $\mathrm{c}$ release from mitochondria to the cytoplasm and may also be important in the carcinogenicity of metallic nickel particles. In addition, the results may be useful as an important reference when comparing the toxicities of different nickel compounds. 


\section{Background}

Nickel is a widely distributed metal that is industrially applied in many forms. The high consumption of various nickel products inevitably leads to occupational and environmental pollution [1]. Carcinogenicity of nickel compounds has been well documented [2-4]. However, the carcinogenic effect of metallic nickel is still unclear [5]. Evidence indicates that various nickel compounds, but not metallic nickel, cause pulmonary inflammation, fibrosis, emphysema, and cancer [6]. The International Agency for Research on Cancer (IARC), therefore, classified all nickel compounds as human carcinogens in 1990 [7]. The available epidemiological studies on the carcinogenicity of metallic nickel are limited by inadequate exposure information, low exposures, short follow-up periods, and small numbers of cases [8]. But evidences from studies in experimental animals suggest that metallic nickel is reasonably anticipated to be a human carcinogen [5].

The metallic nickel nanoparticle is a product with many new characteristics, which include a high level of surface energy, high magnetism, low melting point, high surface area, and low burning point. Therefore, it can be widely used in modern industries [9]. However, these same properties of metallic nickel nanoparticles may present unique potential health impact [10]. Based on the fact that $\mathrm{TiO}_{2}$ nanoparticles are more toxic than $\mathrm{TiO}_{2}$ fine particles [11], the pathological effects of nickel compounds and metallic nickel may also depend on their particle size. Nickel compound (acetate)-induced apoptosis has been reported in Chinese hamster ovary cells [12] and $\mathrm{T}$ cell hybridoma cells [13]. But the mechanism of cell death induced by metallic nickel nano- and fine particles has not been clearly elucidated.

Apoptosis is a highly regulated process that is involved in pathological conditions [14]. Diseases may be caused by a malfunction of apoptosis. An inefficient elimination of mutated cells may favor carcinogenesis [15]. However, excessive apoptosis was shown to contribute to pulmonary fibrosis in mice [16]. Furthermore, enhanced apoptosis may indirectly trigger compensatory cell proliferation to ensure tissue homeostasis and promote the fixation of mutagenic events. Evidence indicates that apoptosis is also involved in pulmonary disorders, such as acute lung injury, diffuse alveolar damage, and idiopathic pulmonary fibrosis [16,17]. Therefore, the apoptotic properties may be important in the mechanisms of pathogenicity and carcinogenicity induced by the metallic nickel particles.

Accordingly, the aim of the present study is to compare the cytotoxicity and apoptosis induced by metallic nickel nano- and fine particles, and to elucidate the mechanisms of cell death induced by these particles in vitro.

\section{Methods \\ Materials}

Metallic nickel nanoparticles, average size $80 \mathrm{~nm}$, were purchased from Inframat Advanced Materials, LLC (Farmington, CT). Metallic nickel fine particles, average size of $3 \mu \mathrm{m}$, were purchased from Sigma-Aldrich (Milwaukee, WI). Eagle's minimal essential medium (EMEM) was obtained from Lonza (Walkersville, MD). Fetal bovine serum (FBS), trypsin, pencillin/streptomycin and Lglutamine were purchased from Life Technologies, Inc. (Gaithersburg, MD). YO-PRO-1 [YP, $1 \mathrm{mM}$ solution in dimethyl sulfoxide (DMSO)] and propidium iodide (PI, $1.0 \mathrm{mg} / \mathrm{ml}$ in water) were purchased from Invitrogen (Carlsbad, CA). Anti-h/m caspase- 8 antibody was obtained from R\&D systems (Minneapolis, MN). Total Akt (Akt), phospho-Akt (p-Akt, ser 473), BID, and cleaved caspase-3 antibodies were purchased from Cell Signaling Technology (Beverley, MA). All other antibodies were obtained from Santa Cruz Biotechnology Co. (Santa Cruz, CA). Cell proliferation kit I (MTT assay kit) was obtained from Roche Applied Science (Penzberg, Germany). Mitochondria Staining Kit was purchased from Sigma-Aldrich (Saint Louis, MO).

\section{Preparation of metallic nickel nano- and fine particles}

Stock solutions of metallic nickel nano- or fine particles were prepared by sonification on ice using a Branson Sonifier 450 (Branson Ultrasonics Corp., Danbury, CT) in sterile PBS $(10 \mathrm{mg} / \mathrm{ml})$ for $30 \mathrm{sec}$, then kept on ice for 15 $\mathrm{sec}$ and sonicated again for a total of $3 \mathrm{~min}$ at a power of $400 \mathrm{~W}$. Before use, these particles were diluted to a designed concentration in fresh culture medium. All samples were prepared under sterile conditions.

\section{Surface area and size distribution measurements}

Surface area of metallic nickel particles was measured using the Gemini 2360 Surface Area Analyzer (Mircomeritics; Norcross, GA) with a flowing gas technique according to the manufacturer's instructions. The size distribution of metallic nickel particles was detected using scanning electron microscopy (SEM). Briefly, metallic nickel particles were prepared by sonification. Then, the samples were diluted in double-distilled water and air dried onto a carbon planchet. Images were collected on a scanning electron microscope (Hitachi S-4800; Japan) according to the manufacturer's instructions. Optimas 6.5 image analysis software (Media Cybernetics; Bethesda, MD) was used to measure the diameter of metallic nickel particles.

\section{Cell culture}

Mouse epidermal JB6 cells were maintained in 5\% FBS EMEM containing $2 \mathrm{mM}$ L-glutamine and $1 \%$ penicillinstreptomycin $(10,000 \mathrm{U} / \mathrm{ml}$ penicillin and $10 \mathrm{mg} / \mathrm{ml}$ streptomycin) at standard culture conditions $\left(37^{\circ} \mathrm{C}, 80 \%\right.$ 
humidified air, and 5\% $\mathrm{CO}_{2}$ ). For all treatments, cells were grown to $80 \%$ confluence.

\section{Cytotoxicity assay}

Cytotoxicity of metallic nickel nano- or fine particles to JB6 cells was assessed by a MTT assay kit following the manufacturer's instructions. Briefly, cells were plated in $100 \mu \mathrm{l}$ EMEM at a density of $10^{4}$ cells/well in a 96 well plate. The cells were grown for $24 \mathrm{~h}$ and treated with various concentrations of metallic nickel particles. After $24 \mathrm{~h}$ incubation, $10 \mu \mathrm{l}$ MTT labeling reagent was added in each well and the plates were further incubated for $4 \mathrm{~h}$. Afterward, $100 \mu \mathrm{l}$ solubilization solution was added to each well and the plate was incubated overnight at $37^{\circ} \mathrm{C}$. The optical density (OD) of the wells was measured at a wavelength of $575 \mathrm{~nm}$ with reference of $690 \mathrm{~nm}$ using an ELISA plate reader. Results were calibrated with OD measured without cells.

\section{Detection of apoptosis}

YP staining was used to determine if cell death induced by metallic nickel particles was apoptotic. Briefly, JB6 cells were seeded onto a 24-well plate overnight. Then, cells were treated with/without various concentrations of metallic nickel nano- or fine particles for $24 \mathrm{~h}$. Before microscopy, YP was added into the cultures $(10 \mu \mathrm{g} / \mathrm{ml})$ for $1 \mathrm{~h}$. Then, cells were washed two times with EMEM medium. Apoptotic cells were monitored using a fluorescence microscope (Axiovert $100 \mathrm{M}$; Zeiss, Germany). Percentage of cells exhibiting apoptosis was calculated.

\section{Identification of apoptosis}

Dual staining using YP and PI was used to distinguish between apoptosis and necrosis as described by Debby and Boffa $[18,19]$ with some modifications. JB6 cells were seeded onto a 24-well plate and incubated overnight. Then, cells were treated with/without various concentrations of metallic nickel nano- or fine particles. One hour later, YP and PI were added into the cultures with a final concentration of $10 \mu \mathrm{g} / \mathrm{ml}$ and $1 \mu \mathrm{M}$, respectively. The progression of cell death in the living cultures was monitored at different time points on a fluorescence microscope (Axiovert $100 \mathrm{M}$ ). YP stained cells were detected with blue excitation filter. PI stained cells were measured by green excitation filter.

\section{Western blot analysis}

Briefly, cells were plated onto a 6-well plate. The cultures were grown $24 \mathrm{~h}$ and then starved in 0.1\% FBS EMEM overnight. Cells were treated with/without metallic nickel nano- or fine particles. After treatment, the cells were extracted with $1 \times$ SDS sample buffer supplemented with protease inhibitor cocktail (Sigma-Aldrich). Protein concentrations were determined using the bicinchoninic acid method (Pierce; Rockford, IL). Equal amounts of proteins were separated by $4-12 \%$ Tris glycine gels. Immunoblots for expression of Fas, FADD, caspase-8, DR3, death receptor 6 (DR6), tumor necrosis factor-receptor 2 (TNF-R2), caspase-3, caspase-6, caspase-9, BID, cleaved BID, Bcl-2, BAX, cytochrome $c$, AIF, beta-actin, and lamin A were detected. Experiments were performed three or more times, and equal loading of protein was ensured by measuring total Akt, and alpha- or beta-tubulin expression.

To prepare the subcellular fractionation, cells were washed twice with cold PBS. Then, cells were lysed in 100 $\mu \mathrm{l}$ of cold isolation buffer A (20 mM Hepes $/ 10 \mathrm{mM} \mathrm{KCl} /$ $1.5 \mathrm{mM} \mathrm{MgCl} / 1 \mathrm{mM}$ EDTA/ $1 \mathrm{mM}$ EGTA/ $1 \mathrm{mM}$ DTT) supplemented with protease inhibitor cocktail and 250 $\mathrm{mM}$ sucrose. After incubating on ice for $15 \mathrm{~min}$, the cells were broken by passing through 22-gauge needles 25 times. The lysate was centrifuged at $800 \times \mathrm{g}$ for $5 \mathrm{~min}$ to remove unbroken cells and nuclei. The supernatant was then re-centrifuged $\left(10,000 \times \mathrm{g}, 30 \mathrm{~min}, 4^{\circ} \mathrm{C}\right)$ to obtain a pellet. The resultant supernatant was the cytosolic fraction and the pellet contained mitochondria. The cytosolic fraction was diluted using $100 \mu \mathrm{l}$ of $2 \times$ SDS sample buffer. The mitochondrial pellet was resuspended in $1 \times$ SDS sample buffer.

\section{IP western blot analysis}

After treatment, JB6 cells were lysed in buffer B $(20 \mathrm{mM}$ Tris- $\mathrm{HCl}$, pH 7.5, containing $150 \mathrm{mM} \mathrm{NaCl}, 2 \mathrm{mM}$ EDTA, $1 \%$ Triton $\mathrm{X}-100,10 \%$ glycerol, and $10 \mu \mathrm{l} / \mathrm{ml}$ protease inhibitor cocktail) for $15 \mathrm{~min}$ at $4^{\circ} \mathrm{C}$. Lysates were centrifuged at $25,000 \times g$ for $15 \mathrm{~min}$. Protein concentrations of the supernatants were determined. Equal amounts of proteins were immunoprecipitated overnight with rabbit anti-caspase- 8 antibody $(1: 200)$ at $4{ }^{\circ} \mathrm{C}$. The supernatant was further incubated with $20 \mu$ l of protein A/G-agarose slurry for $3 \mathrm{~h}$ at $4^{\circ} \mathrm{C}$. Beads were pelleted, washed three times in buffer B, and finally boiled in $1 \times$ SDS sample buffer. Proteins were separated by $4-12 \%$ Tris glycine gels. Fas and FADD proteins were detected as described in western blot analysis.

\section{Detection of mitochondrial membrane permeability}

JB6 cells were seeded onto a 24-well plate overnight. Cells were treated with/without metallic nickel nano- or fine particles for $24 \mathrm{~h}$. Changes of mitochondrial membrane permeability were evaluated using a mitochondrial staining kit (JC1 staining) according to the manufacturer's instructions. Briefly, a staining mixture was prepared by mixing the staining solution with an equal volume of the EMEM medium. Cells were incubated in the staining mixture $(0.4 \mathrm{ml} /$ well $)$ for $30 \mathrm{~min}$ at $37^{\circ} \mathrm{C}$ in a humidified atmosphere containing $5 \% \mathrm{CO}_{2}$. Thereafter, cells were washed two times in medium, followed by addition of fresh medium. Mitochondrial membrane permeability 
was monitored on a fluorescence microscope (Axiovert $100 \mathrm{M})$.

\section{Statistical analysis}

Data are presented as means \pm standard errors (S.E.) of $n$ experiments/samples. Significant differences were determined using R software or the Student's $t$-test. Significance was set at $p \leq 0.05$.

\section{Results \\ Surface area and size distribution of metallic nickel particles}

To measure the surface area and size distribution of nickel particles, Gemini 2360 Surface Area Analyzer and scanning electron microscopy were used, respectively. The average surface area of metallic nickel nanoparticles was $4.36 \mathrm{~m}^{2} / \mathrm{g}$ compared to $0.40 \mathrm{~m}^{2} / \mathrm{g}$ for fine particles. The average size distribution of metallic nickel nano- and fine particles is $92.32 \mathrm{~nm}$ and $3.34 \mu \mathrm{m}$, respectively (Table 1).

\section{SEM images of the metallic nickel particles}

Metallic nickel nano- or fine particles were prepared by sonification. Then, the samples were diluted in doubledistilled water and air dried onto a carbon planchet. SEM images were captured on a scanning electron microscope (Figure 1A and 1B).

\section{Effects of metallic nickel particles on cell viability and apoptotic induction}

To determine whether there is a difference in the cytotoxicity induced by different sizes of metallic nickel particles, various concentrations $\left(0.1-20 \mu \mathrm{g} / \mathrm{cm}^{2}\right)$ of metallic nickel nano- or fine particles were used to study the effects on cell viability in JB6 cells by MTT assay. Treatment of JB6 cells with metallic nickel particles for $24 \mathrm{~h}$ caused a dosedependent cytotoxicity (Figure 2A). Cytotoxicity induced by metallic nickel nanoparticles was significantly higher than that induced by fine particles.

To study the apoptosis induced by metallic nickel nanoor fine particles, YP staining was used. JB6 cells were treated with various concentrations of metallic nickel nano- or fine particles from 0.1 to $20 \mu \mathrm{g} / \mathrm{cm}^{2}$ for $24 \mathrm{~h}$. Results indicated that both metallic nickel nano- and fine particles induced JB6 cell apoptosis (Figure 2B). The per-

Table I: Surface area and size distribution of metallic nickel particles

\begin{tabular}{|c|c|c|}
\hline & Nickel fine particles & Nickel nanoparticles \\
\hline Surface area $\left(\mathrm{m}^{2} / \mathrm{g}\right)$ & $0.4 \pm 0.01$ & $4.36 \pm 0.02$ \\
\hline Average size & $3.34 \pm 0.67(\mu \mathrm{m})$ & $92.32 \pm 29.69(\mathrm{~nm})$ \\
\hline
\end{tabular}

Surface area was determined by gas absorption and particle size by scanning electron microscopy. Values are means \pm S.E. of six independent assays. centages of apoptotic cells were significantly higher in cells treated with nanoparticles than fine particles between the concentration of 0.5 and $5 \mu \mathrm{g} / \mathrm{cm}^{2}$ (Figure 2C). At the concentration $5 \mu \mathrm{g} / \mathrm{cm}^{2}$, there was a 4 -fold increase in apoptosis induced by nanoparticles compared to fine particles.

\section{Identification of apoptosis induced by metallic nickel particles}

To distinguish between apoptosis and necrosis induced by metallic nickel nano- or fine particles, a dual staining assay using YP and PI was applied. The results showed that both metallic nickel nano- and fine particles (data not shown) could induce JB6 cell apoptosis demonstrated by the positive staining of YP at an early exposure time ( $24 \mathrm{~h}$ ) in a dose range of $0.1-20 \mu \mathrm{g} / \mathrm{cm}^{2}$ (Figure 3A). Enhanced dose $\left(100 \mu \mathrm{g} / \mathrm{cm}^{2}, 24 \mathrm{~h}\right)$ or extended treatment $(20 \mu \mathrm{g} /$ $\mathrm{cm}^{2}, 48 \mathrm{~h}$ ) resulted in necrosis or late apoptosis demonstrated by the positive staining of both YP and PI (Figure $3 \mathrm{~A}$ and $3 \mathrm{~B})$.

\section{Effects of metallic nickel particles on caspase-8, Fas, FADD, DR3, DR6, TNF-R2, p-Akt, DISC, lamin A, beta- actin, $B I D, B C l-2$, and $B A X$}

Previous studies have demonstrated that apoptosis activates an upstream protease caspase- $8[20,21]$. In this study, JB6 cells were treated with $20 \mu \mathrm{g} / \mathrm{cm}^{2}$ of metallic nickel nano- or fine particles for 30, 60, 120, and $180 \mathrm{~min}$. Protein expressions were detected by western-blot. Results indicated that caspase- 8 was activated by these particles (Figure 4A).

Two important signals are known to be involved in apoptosis, which include the TNF and the Fas-Fas ligand-mediated pathways. Both involve the TNF receptor family coupled to extrinsic signals [22]. To investigate the involvement of extrinsic signals in the apoptotic process induced by metallic nickel particles, expression of the TNF family members of Fas, FADD, DR3, DR6, and TNF-R2 was examined. Results demonstrated that metallic nickel particles activated Fas, FADD and DR3. However, no obvious change was found in the protein expression of DR6 or TNF-R2 (Figure 4A).

Akt is a well-characterized member of PI3 kinase-mediated signaling pathways, regulating cell growth, apoptosis, as well as other cellular responses. Akt activation inhibits apoptosis by phosphorylating the Bcl-2 related proteins. In addition, Akt activation is sufficient to inhibit the release of cytochrome $c$ from mitochondria and the alterations in the inner mitochondrial membrane potential [23]. In this study, results indicated that both metallic nickel nano- and fine particles induced Akt phosphorylation in a time-dependent manner (Figure 4A). 

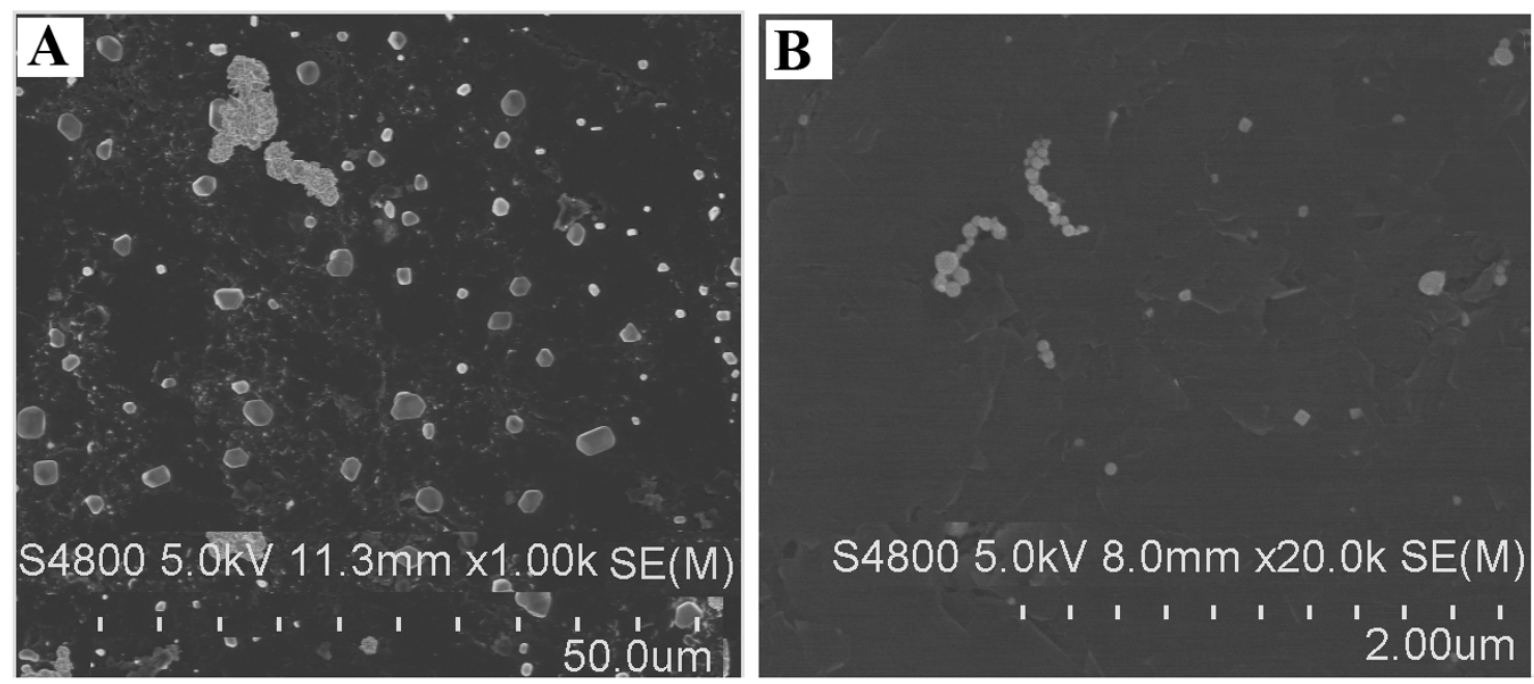

Figure I

SEM images of metallic nickel particles. SEM images of metallic nickel fine $(\mathbf{A})$ or nanoparticles (B) were captured on a scanning electron microscope.

As caspase-8 activation was detected, we further determined the involvement of the DISC formation in the process of apoptosis induced by metallic nickel particles. The interaction between Fas and FasL results in the formation of the DISC, which consist of Fas, FADD, and caspase- 8 [22]. To investigate the formation of DISC, IP western blot was used. JB6 cells were treated with $20 \mu \mathrm{g} /$ $\mathrm{cm}^{2}$ metallic nickel nano- or fine particles for 30, 60, 120, and $180 \mathrm{~min}$. Anti-caspase- 8 IP revealed an interaction of Fas and FADD with caspase-8, demonstrating DISC formation and the initiation of Fas-induced apoptotic pathway (Figure 4B).

The cellular morphology associated with the apoptotic process has been well characterized by membrane blebbing, formation of apoptotic bodies, and chromosome condensation. These apoptotic changes are the result of the cleavage of cellular proteins, such as lamin and actin $[24,25]$. In this study, JB6 cells were treated with $20 \mu \mathrm{g} /$ $\mathrm{cm}^{2}$ metallic nickel nano- or fine particles for $1,3,6$, and $8 \mathrm{~h}$. Western blot revealed that the cleavages of lamin A and beta-actin were detected as early as $1 \mathrm{~h}$ post-exposure. Both particles induced lamin A cleavages in a timedependent manner (Figure 4C).
BID, a proapoptotic member of the Bcl-2 family, is a physiological substrate of caspase- 8 which causes mitochondrial damage [26]. The results demonstrated that metallic nickel nano- or fine particles induced BID cleavage in a time-dependent manner. Interestingly, Bcl-2, an antiapoptotic protein, was up-regulated. BAX, a proapoptotic member of Bcl-2 family, was down-regulated (Figure 4D).

\section{Effects of metallic nickel particles on AIF, cytochrome c, caspase-3, -6, and -9}

AIF is a recently characterized proapoptotic mitochondrial protein [27]. It is normally confined to the mitochondrial inter membrane space. After release from mitochondria into the cytoplasm, AIF can stimulate cell apoptosis [28]. To test the effects of metallic nickel particles, JB6 cells were treated with $20 \mu \mathrm{g} / \mathrm{cm}^{2}$ nano- or fine particles for $1,3,6$, and $8 \mathrm{~h}$. Western blots revealed that both nano- and fine particles induced mitochondrial AIF up-regulation and release from mitochondria to the cytoplasm after $1 \mathrm{~h}$ treatment (Figure 5A).

Cytochrome $c$ is an important apoptotic factor in the intrinsic apoptotic pathway which is released into the cytoplasm from the mitochondria in response to proap- 

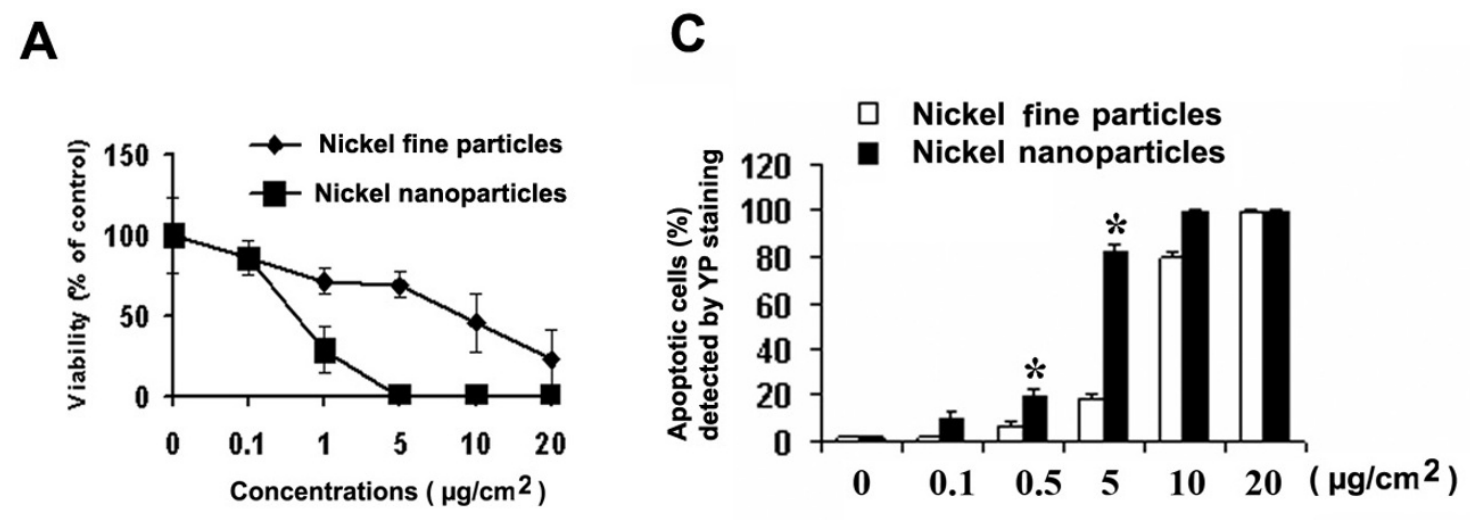

B

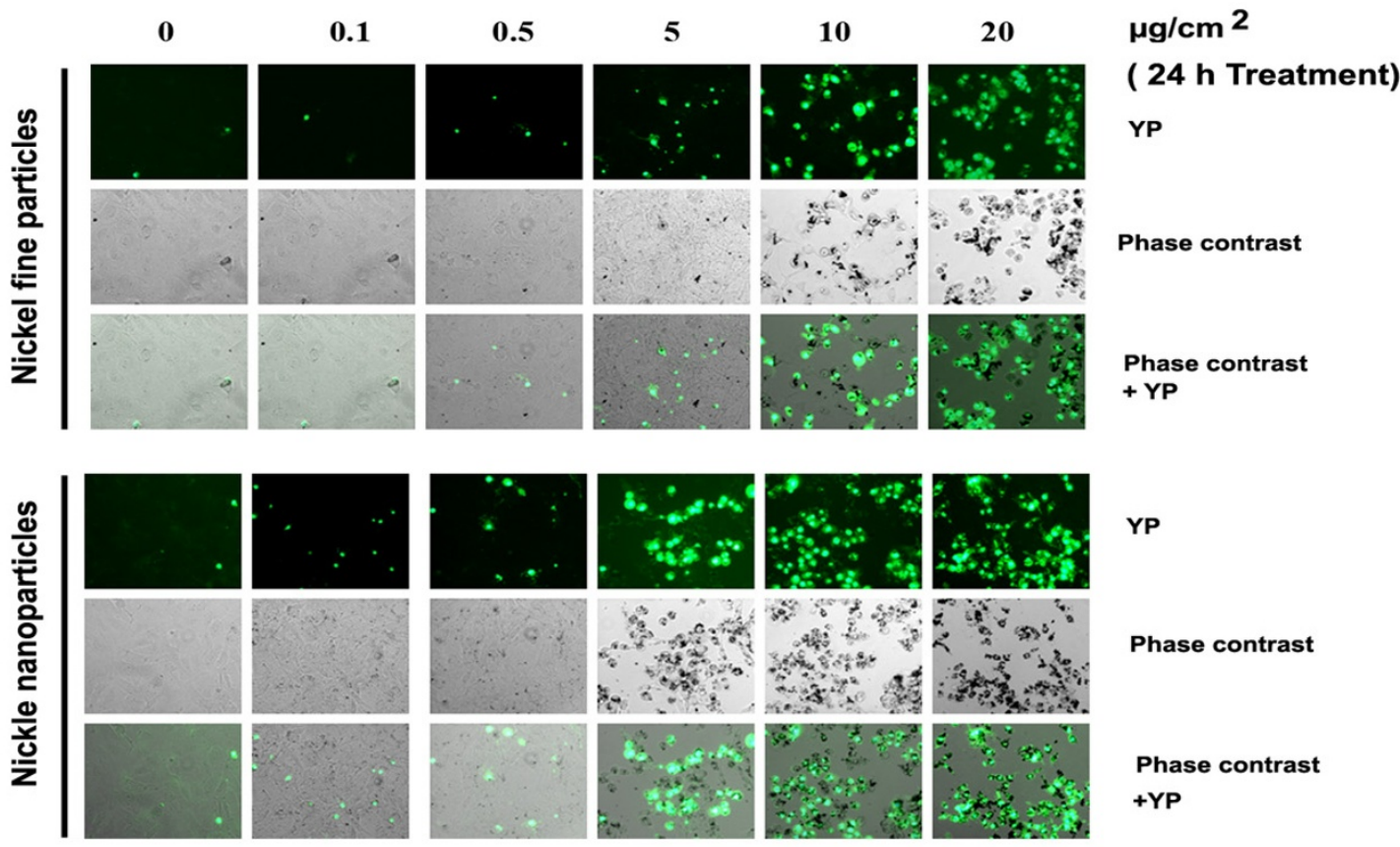

Figure 2

Effects of metallic nickel particles on cell viability and apoptotic induction. JB6 cells were exposed to various concentrations of metallic nickel nano- or fine particles for $24 \mathrm{~h}$. Cell viability was detected by MTT assay. Significantly less viability was observed in cells treated with nanoparticles compared to fine particles analyzed by $R$ software $(p<0.05)$. Data shown are means \pm S.E. of four independent assays $(\mathbf{A})$. Apoptosis induced by metallic nickel nano- or fine particles was detected by YP staining (B, 10x magnification). Metallic nickel nanoparticles induced more apoptosis than fine particles at 0.5 and $5 \mu \mathrm{g} / \mathrm{cm}^{2}$ analyzed by Student's $t$-test $(p<0.05)$ indicated by $*(\mathbf{C})$. Data shown are means \pm S.E. of three independent assays. 
A
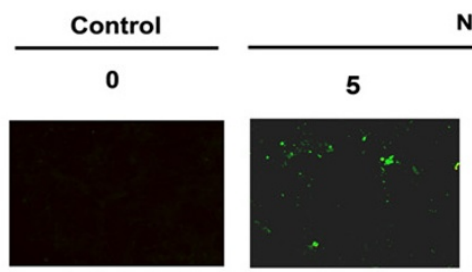

Nickel nanoparticles
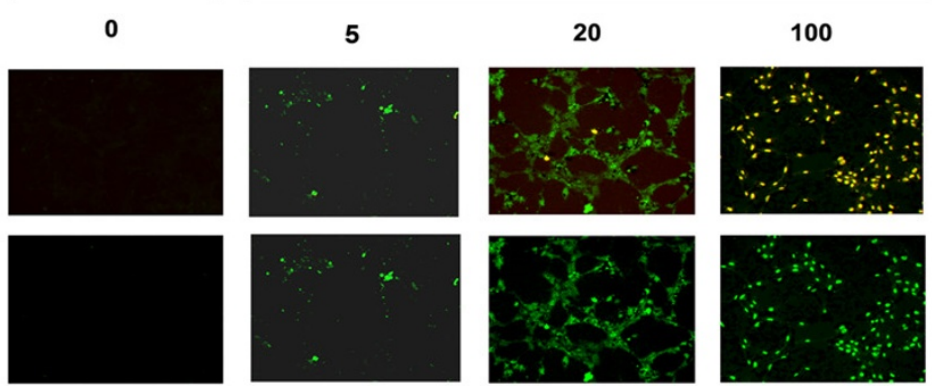

$\mu \mathrm{g} / \mathrm{cm} 2$

(24 h Treatment)

$\mathbf{Y P}+\mathbf{P I}$
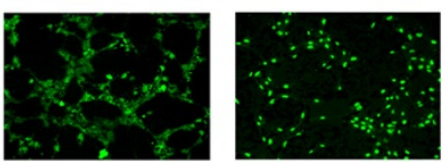

YP
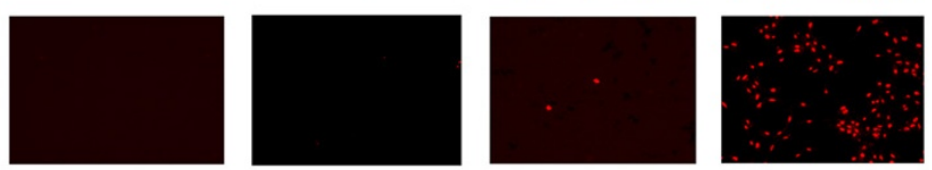

PI
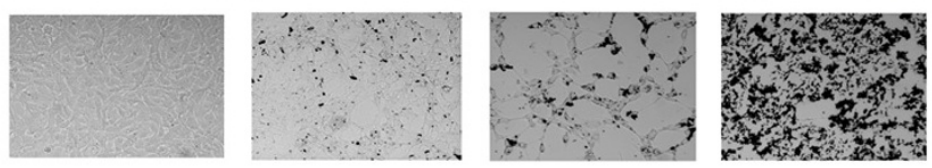

Phase contrast

B
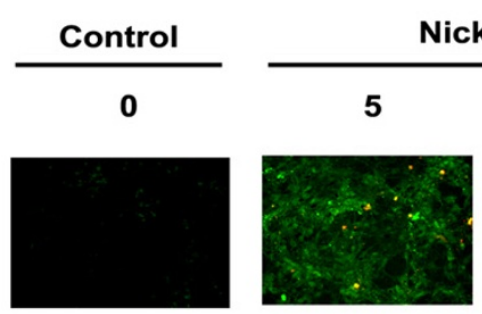

Nickel nanoparticles
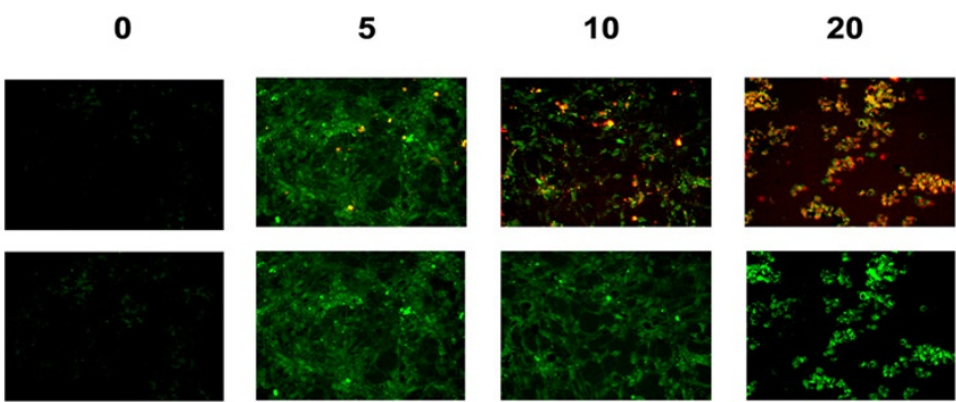

$\mu \mathrm{g} / \mathrm{cm}^{2}$

(48 $\mathrm{h}$ Treatment)
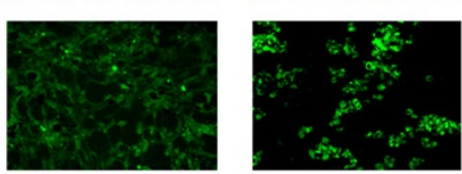

$\mathbf{Y P}+\mathbf{P I}$
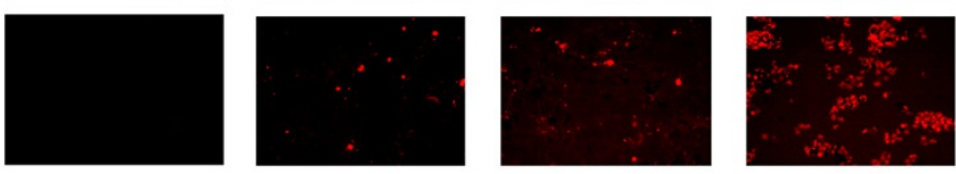

YP

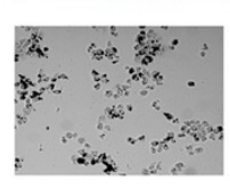

Phase contrast

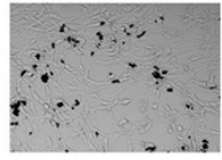

Figure 3

Identification of apoptosis induced by metallic nickel nanoparticles. JB6 cells were seeded onto 24-well plate and incubated overnight. Cells were treated with/without metallic nickel nanoparticles. Continuous monitoring of apoptosis and necrosis was conducted by using a dual fluorescence dye assay after $24 \mathrm{~h}$ treatment $(\mathbf{A})$ or $48 \mathrm{~h}$ treatment (B). 
A

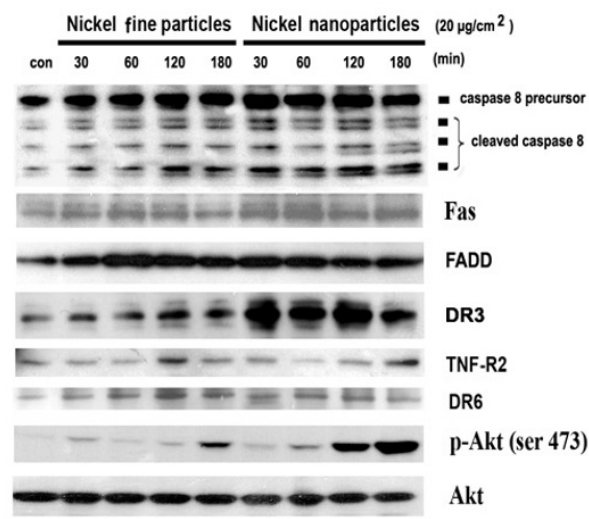

B

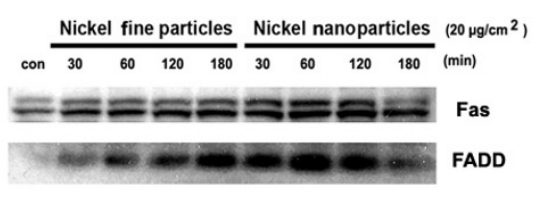

IP/Caspase-8 IB/FAS and FADD
C

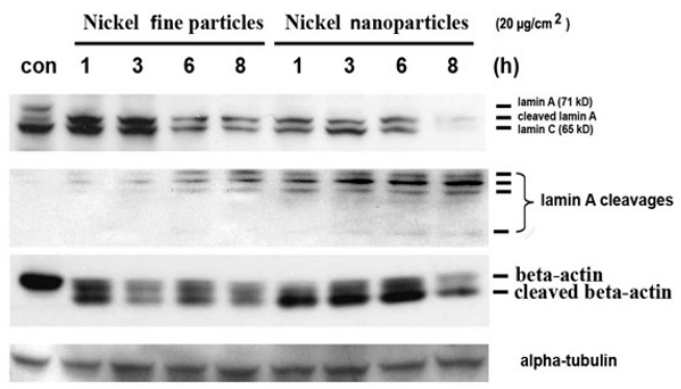

D

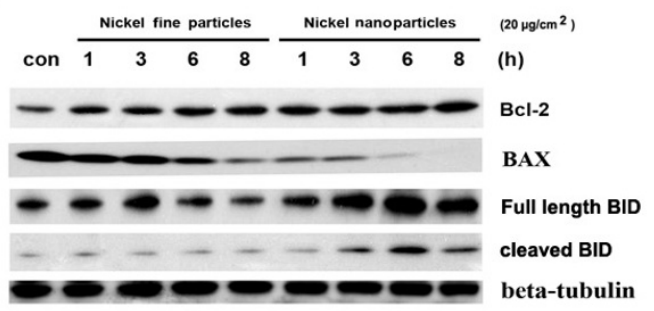

Figure 4

Effects of metallic nickel particles on caspase-8, Fas, FADD, DR3, DR6, TNF-R2, p-Akt, DISC, lamin A, betaactin, BID, Bcl-2, and BAX. Cells were treated with $20 \mu \mathrm{g} / \mathrm{cm}^{2}$ metallic nickel particles for 30,60, 120, and $180 \mathrm{~min}$. Expressions of caspase-8, Fas, FADD, DR3, DR6, TNF-R2, and p-Akt were analyzed by western blot (A). To investigate the formation of DISC, IP western blot was used (B). Cells were treated with metallic nickel particles for I, 3, 6, and $8 \mathrm{~h}$. Effects of metallic nickel particles on lamin A, beta-actin, and $\mathrm{Bcl}-2$ family were detected by western blot (C and $\mathbf{D})$.

optotic stimuli [29]. To investigate the possible involvement of cytochrome $c$ release in the process of apoptosis induced by metallic nickel particles, JB6 cells were treated with $20 \mu \mathrm{g} / \mathrm{cm}^{2}$ of metallic nickel nano- or fine particles for 1, 3, 6, $8 \mathrm{~h}$. Western blot analysis indicated that cytochrome $c$ was not released from the mitochondria into the cytoplasm although metallic nickel particles could induce cytochrome $c$ up-regulation (Figure 5B).

Caspases are a family of cysteine proteases which play essential roles in apoptosis, necrosis and inflammation [30]. Eleven caspases have so far been identified in humans. There are two types of apoptotic caspases: initiator caspases and effector caspases. Initiator caspases (e.g. caspase-8) cleave inactive pro-forms of effector caspases, thereby activating them. Effector caspases (e.g. caspase-3 and -6) in turn cleave other protein substrates resulting in the apoptotic process. Since activation of caspase- 8 was detected, we next examined the possible involvement of caspase- $3,-6$, and -9 in the process of apoptosis induced by metallic nickel particles. Results indicated that metallic nickel particles induced only a slight activation of caspase$3,-6$, and -9 . Interestingly, caspase-3 precursor was significantly up-regulated by metallic nickel particles (Figure $5 \mathrm{C})$.

\section{Effects of metallic nickel particles on mitochondrial membrane permeability}

Mitochondrial membrane permeability change is a hallmark for apoptosis [31]. JB6 cells were treated with/without various concentrations of metallic nickel particles for $24 \mathrm{~h}$. Mitochondrial membrane permeability was evalu- 
A

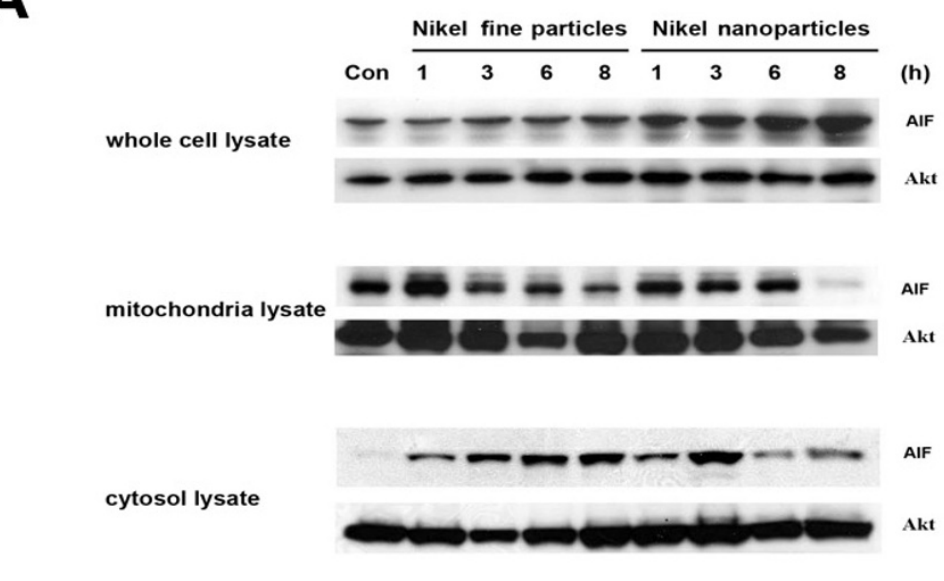

B

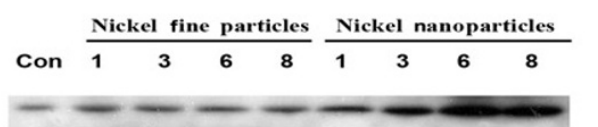

(h)

whole cell lysate

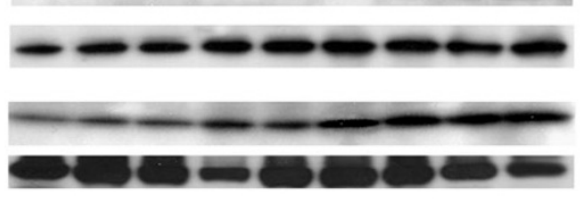

cytochrome c

whole cell lysate

mitochondria lysate

cytochrome c

Akt

cytosol lysate

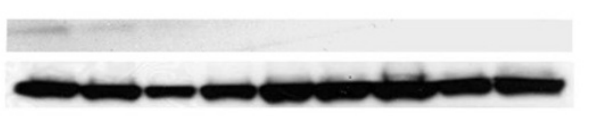

cytochrome c

Akt

C
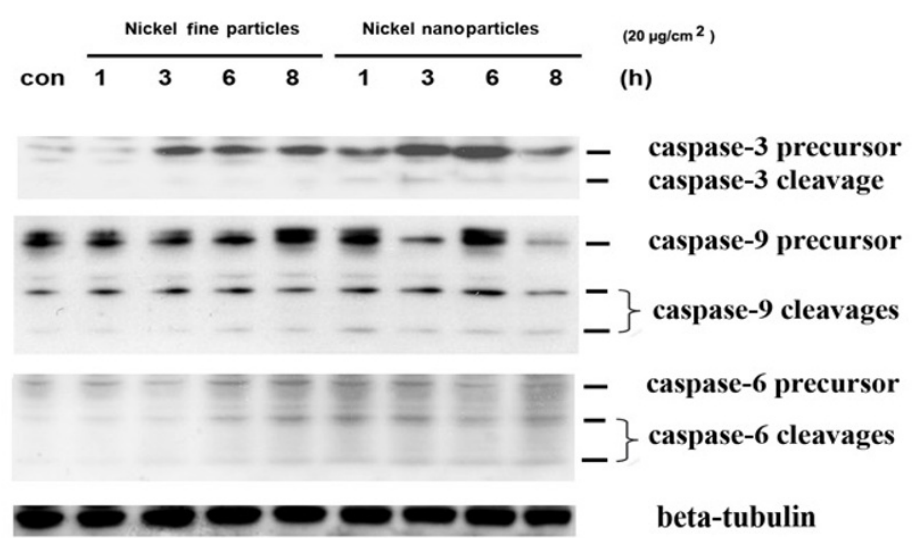

\section{Figure 5}

Effects of metallic nickel particles on AIF, cytochrome c, and caspase-3, -6, and -9. To determine the effects of metallic nickel particles on AIF, cytochrome $c$, and caspase-3, -6, and -9, JB6 cells were seeded onto a 6-well plate. After $24 \mathrm{~h}$ incubation, cells were starved in $0.1 \%$ FBS EMEM overnight. Then, cells were treated with $20 \mu \mathrm{g} / \mathrm{cm}^{2}$ metallic nickel particles for I, 3, 6, and $8 \mathrm{~h}$. Western blot analysis was used to detect the effects of metallic nickel particles on AIF (A), cytochrome $c$ (B), and caspase-3, -6 , and -9 (C). 
ated using a mitochondrial staining kit according to the manufacturer's instructions. The results indicated that neither metallic nickel nano- nor fine particles induced any significant change in the mitochondrial membrane permeability compared to negative control after $24 \mathrm{~h}$ treatment. Positive control cells treated with $0.5 \mu \mathrm{l}$ valinomycin/well for $1 \mathrm{~h}$ showed a significant effect on the mitochondrial membrane permeability (Figure 6A and $6 \mathrm{~B})$.

\section{Discussion}

Nickel and nickel compounds are widely used in industries. In occupational settings, workers are exposed to a variety of nickel compounds, nickel alloys, as well as metallic nickel. About $10 \%$ of all the primary nickel produced is used in metallic form [5]. Human exposure to nickel or its compounds has the potential to produce a

A

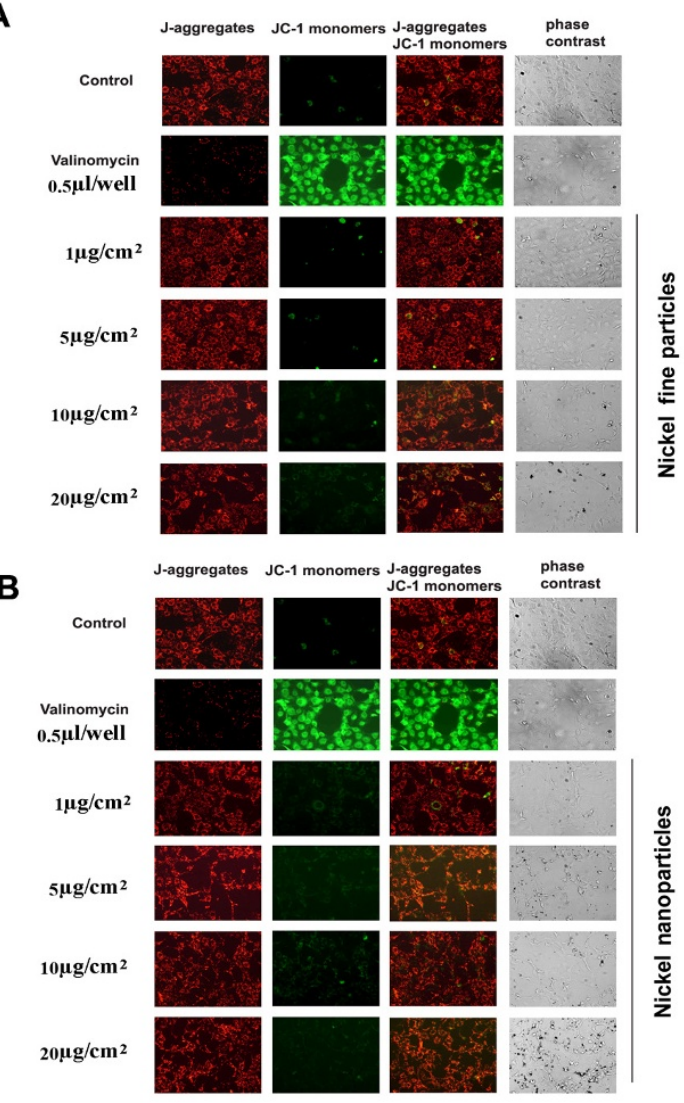

Figure 6

Effect of metallic nickel particles on mitochondrial membrane permeability. JB6 cells were treated with various concentrations of metallic nickel nano- or fine particles for $24 \mathrm{~h}$. A mitochondrial staining kit was used to detect the mitochondrial membrane permeability induced by metallic nickel fine (A) or nanoparticles (B). variety of pathological effects. The most important adverse health effects due to nickel exposure are skin allergies, lung fibrosis, and lung cancer [7].

With the increase use of nanoparticles in modern industries, inhaled nanoparticles are increasingly being recognized as a potential health threat [32]. It is well known that the toxicity of particles to the lung in both occupational and environmental settings is not only related to exposure but also to the particle size. Accordingly, metallic nickel nanoparticles may be more toxic than the conventional metallic nickel fine particles.

In the present study, results show that both metallic nickel nano- and fine particles induce a dose-related increase in cytotoxicity in JB6 cells after 24 h exposure. In addition, metallic nickel nanoparticles are more toxic than fine particles. Our in vitro finding is in agreement with the previous in vivo reports that metallic nickel nanoparticles are more toxic on the bronchoalveolar lavage fluid in rats than metallic nickel fine particles [9]. Apoptosis is a programmed form of cell death which is now widely recognized as being of critical importance in health and disease. Although studies have demonstrated that nickel compounds induce cell apoptosis [12], the molecular pathways have not been well investigated. It is generally accepted that cell death can either result in apoptosis or necrosis. Our results suggest that both metallic nickel nano- and fine particles induce JB6 cell death through apoptosis, but not necrosis, at early exposure time in a certain dose range. With the treatment duration prolonged or treatment dose enhanced, both metallic nickel nano- and fine particles can induce JB6 cells necrosis or late apoptosis. For the quantification of apoptosis, we carried out YP staining to determine the apoptotic cells induced by various concentrations of metallic nickel particles. The results showed that both nano- and fine particles induce JB6 cell apoptosis in a dose response manner after $24 \mathrm{~h}$ treatments in a dose range of $0.1-20 \mu \mathrm{g} / \mathrm{cm}^{2}$. At concentrations of 5 $\mu \mathrm{g} / \mathrm{cm}^{2}$, the number of apoptotic cells induced by nanoparticles was 4 fold higher than fine particles. Our results suggest that both metallic nickel nano- and fine particles are cytotoxic in JB6 cells, while metallic nickel nanoparticles show higher cytotoxicity and apoptosis induction than fine particles. In an inhalation study in rats, Oberdörster et al found $\mathrm{TiO} 2$ nanoparticles to be more inflammatory than fine particles [11]. When normalized to surface area, the authors found that the dose-response curves for the nano- and fine particles were similar, suggesting that the pulmonary inflammation was mediated by surface effects. In the present study, surface area of metallic nickel nanoparticles is 11-fold greater than fine particles. However, metallic nickel nanoparticles exhibited potency for toxicity and apoptosis which was somewhat less than 11-fold greater than fine particles. 
Therefore, surface area tends to over correct for the greater toxicity probably because it over estimates the surface area of agglomerates.

In mammals, signaling cascades culminating in apoptotic cell death can be divided into intrinsic or extrinsic pathways. The extrinsic pathway is activated upon ligation of death receptors. The intrinsic pathway can be initiated by cellular stresses such as cytochrome $c$ release from mitochondria into the cytoplasm. Our results indicate that metallic nickel particles induced Fas, FADD, DR3, and caspase- 8 up-regulation. DISC formation by Fas, FADD and caspase- 8 was also found. The formation of the DISC signaling platform may play an important role in the process of activation of caspase- 8 . Our results suggest that, in the apoptotic process induced by metallic nickel particles, the extrinsic signal pathway is initiated. To investigate the involvement of intrinsic pathways in the apoptotic process induced by metallic nickel particles, cytochrome $c$ release was examined. Our results show that, although both metallic nickel nano- and fine particles produced upregulation of cytochrome $c$ in the mitochondria, no obvious cytochrome $c$ release was detected in the apoptotic process. In addition, mitochondrial permeability assay show that neither metallic nickel nano- nor fine particles induced significant changes in the mitochondrial membrane permeability, which was in parallel with the Western blot results. These results indicate that the apoptotic process induced by metallic nickel particles is initiated by a cytochrome $c$-independent pathway.

Lamins are nuclear membrane structural components that are important for maintaining normal cell functions. Proteolysis of lamins has been observed in different cells undergoing apoptosis [33]. Degradation of lamina proteins can be triggered by both the extrinsic and the intrinsic pathways [34]. Our results show that lamin A was cleaved in JB6 cells treated with nickel particles, suggesting its involvement in the apoptotic process.

Major cytoskeletal filaments, such as actin, can be degraded during the execution phase of apoptosis [35]. The actin cytoskeleton is capable of responding to complex signaling cascades. Recent studies suggest that it may play key roles in regulating apoptosis [36]. Reports indicate that disruption of actin filament integrity promptly induces apoptosis in adherent epithelial cells [37]. In addition, the dynamic state of actin is important in the regulation of ion channels [36]. In the present study, both metallic nickel nano- and fine particles induce beta-actin cleavages after $1 \mathrm{~h}$ treatment in JB6 cells. Our data, combined with a report by Steven et al [37], suggest that the actin cytoskeletal network may act as a target of apoptosis and an early signaling component toward apoptotic com- mitment in the apoptotic process induced by metallic nickel particles.

Recent studies have showed that activation of caspase- 8 leads to cleavage of BID. Cleavage of BID translocates from the cytoplasm to the mitochondria and to induce cytochrome $c$ release $[30,38]$. The $\mathrm{Bcl}-2$ proteins are a family of proteins involved in the response to apoptosis. Some of these proteins such as Bcl-2 are antiapoptotic, while others are proapoptotic. In the present study, neither metallic nickel nano- nor fine particles induced any obvious cytochrome $c$ release. These results suggest that increased Bcl-2 and down-regulated BAX proteins may antagonize the effects of activated BID on the translocation of cytochrome $c$. In addition, accumulating evidence suggests that Akt activation is sufficient to inhibit the release of cytochrome $c$ from mitochondria by up-regulating $\mathrm{Bcl}-2$ protein expression and the alterations in the inner mitochondrial membrane potential [23]. In this study, Akt was activated by metallic nickel particles. Except for the inhibitory effect on the release of cytochrome $c$ from mitochondria into cytoplasm, Akt activation may provide the necessary conditions for the selection of cells that have become resistant to apoptosis, which may also be important in the metallic nickelinduced carcinogenic process. Therefore, further research is needed to elucidate the role of activation of $\mathrm{Bcl}-2$ and Akt in the carcinogenicity of metallic nickel particles.

The execution of apoptosis comprises both caspasedependent and caspase-independent processes. AIF was identified as a major player in caspase-independent cell death. AIF is ideally located in the mitochondria to perform a vital normal function in energy production. Translocation of AIF from mitochondria to the cytoplasm can induce cell apoptosis [39]. Evidence shows that the release of AIF is secondary to both activation of caspase- 8 and increasing translocation of BID [39]. In the present study, both metallic nickel nano- and fine particles induced mitochondrial AIF up-regulation and release from mitochondria into the cytoplasm after $1 \mathrm{~h}$ treatment. Furthermore, our findings imply that AIF release may occur independently from changes in mitochondrial inner membrane permeability. It has been reported that after an apoptotic insult, changes in the mitochondrial outer membrane permeability may be enough to induce AIF release from mitochondria into the cytoplasm and the nucleus [40]. It may also be possible that AIF is released from mitochondria into the cytoplasm through a specific channel [41]. Our results are in agreement that the fast release of AIF from mitochondria into cytoplasm is preceded by increasing of the proapoptotic Bcl-2 family member BID. 
Caspases, a family of aspartic acid-specific proteases, are the major effectors of apoptosis. In the present study, caspase-3, -6 and -9 were only slightly activated in the apoptotic process induced by metallic nickel nano- or fine particles. Interestingly, metallic nickel particles induced caspase-3 precursor up-regulation. Our results suggest that apoptosis induced by metallic nickel nano- or fine particles may be mainly through a caspase-independent pathway.

Mitochondria play an important role in the regulation of cell death. Changes in the mitochondrial membrane permeability are considered an early event in apoptosis. Many proapoptotic proteins can be released from the mitochondria into the cytoplasm, following the formation of a pore in the mitochondrial membrane. In this study, neither metallic nickel nanoparticles nor metallic nickel fine particles induced significant changes in the mitochondrial membrane permeability in JB6 cells after $24 \mathrm{~h}$ treatment. These findings imply that, unlike AIF release, cytochrome $c$ release is through a mitochondrial membrane permeability change-dependent manner.

In summary, the major findings of the present study are that metallic nickel nanoparticles elicit higher cytotoxicity and apoptosis induction than fine particles. We also identified that metallic nickel particles could induce JB6 cell death through apoptosis, but not necrosis after 24 h treatment in a dose range of $0.1-20 \mu \mathrm{g} / \mathrm{cm}^{2}$. To our knowledge, this is the first study showing that metallic nickel particles activated Fas, FADD, caspase- 8 , and induced BID cleavage. We provided evidence for DISC formation of Fas-FADD-caspase-8. Another notable finding is that AIF, but not cytochrome $c$, is released from mitochondria into the cytoplasm in the apoptotic process in JB6 cells induced by metallic nickel particles. Notably, upon activation of apoptosis induced by metallic nickel particles in JB6 cells, no significant changes of mitochondrial membrane permeability could be detected. Our results demonstrate that a caspase-8/AIF mediated cytochrome $c$ independent pathway may play a major role in metallic nickel particle-induced apoptosis.

\section{Abbreviations}

MTT: 3-(4,5-dimethylthiazol-2-yl)-2,5-diphenyltetrazolium bromide; FADD: Fas-associated protein with death domain; DR3: death receptor 3; DR6: death receptor 6; IP: Immunoprecipitation; DISC: death-inducing signaling complex; AIF: apoptosis-inducing factor; p-Akt: phosphoAkt; TNF-R2: tumor necrosis factor-receptor 2; IARC: International Agency for Research on Cancer; EMEM: Eagle's minimal essential medium; FBS: fetal bovine serum; DMSO: dimethyl sulfoxide; YP: YO-PRO-1; PI: propidium iodide; SEM: scanning electron microscopy.

\section{Competing interests}

The authors declare that they have no competing interests.

\section{Disclaimer}

The opinions expressed in this article are those of the authors and do not necessarily represent any agency determination or policy.

\section{Authors' contributions}

$\mathrm{JZ}, \mathrm{LB}, \mathrm{XZ}$ and $\mathrm{BJ}$ performed the majority of the experiments. JZ, LB, XS, VC and MD involved in writing the manuscript and designing the overall project. All authors read and approved the final manuscript.

\section{Acknowledgements}

We thank Cunlin Dong for statistical analysis, Diane Schwegler-Berry and Sherri Friend for image analysis, and Donna Pack for surface area analysis. This research was supported in part by $\mathrm{NIH}$ grant(ROIESOI55।8).

\section{References}

I. Hartwig A, Kruger I, Beyersmann D: Mechanisms in nickel genotoxicity: the significance of interactions with DNA repair. Toxicol Lett 1994, 72:353-358.

2. Coogan TP, Latta DM, Snow ET, Costa M: Toxicity and carcinogenicity of nickel compounds. Crit Rev Toxicol 1989, 19:34I-384.

3. Ke Q, Li Q, Ellen TP, Sun H, Costa M: Nickel compounds induce phosphorylation of histone $\mathrm{H} 3$ at serine 10 by activating JNKMAPK pathway. Carcinogenesis 2008, 29: I276-128I.

4. Lu H, Shi X, Costa M, Huang C: Carcinogenic effect of nickel compounds. Molecular and cellular biochemistry 2005, 279:45-67.

5. Sivulka DJ: Assessment of respiratory carcinogenicity associated with exposure to metallic nickel: a review. Regul Toxicol Pharmacol 2005, 43: I I7-133.

6. Benson JM, Burt DG, Cheng YS, Hahan FF, Haley PJ, Henderson RF, Hobbs CH, Pickrell JA, Dunnick JK: Biochemical responses of rat and mouse lung to inhaled nickel compounds. Toxicology 1989, 57:255-266.

7. Kasprzak KS, Sunderman FW Jr, Salnikow K: Nickel carcinogenesis. Mutat Res 2003, 533:67-97.

8. U.S. Department of Health and Human Services PHS, National Toxicology Program: Report on Carcinogens. Eleventh edition. .

9. Zhang Q, Kusaka Y, Zhu X, Sato K, Mo Y, Kluz T, Donaldson K: Comparative toxicity of standard nickel and ultrafine nickel in lung after intratracheal instillation. J Occup Health 2003, 45:23-30.

10. Andrew D, Maynard aEDK: Airborne nanostructured particles and occupational health. Journal of Nanoparticle Research 2005:587-6 I4.

II. Oberdorster G, Ferin J, Lehnert BE: Correlation between particle size, in vivo particle persistence, and lung injury. Environ Health Perspect 1994, 102(Suppl 5): I73-179.

12. Shiao YH, Lee SH, Kasprzak KS: Cell cycle arrest, apoptosis and p53 expression in nickel(II) acetate-treated Chinese hamster ovary cells. Carcinogenesis 1998, 19:1203-1207.

13. Kim K, Lee SH, Seo YR, Perkins SN, Kasprzak KS: Nickel(II)induced apoptosis in murine $\mathbf{T}$ cell hybridoma cells is associated with increased fas ligand expression. Toxicol Appl Pharmacol 2002, 185:4I-47.

14. Steller $\mathrm{H}$ : Mechanisms and genes of cellular suicide. Science 1995, 267: 1445-| 449.

15. Lombaert N, De Boeck M, Decordier I, Cundari E, Lison D, KirschVolders M: Evaluation of the apoptogenic potential of hard metal dust (WC-Co), tungsten carbide and metallic cobalt. Toxicol Lett 2004, 154:23-34.

16. Kuwano K, Miyazaki H, Hagimoto N, Kawasaki M, Fujita M, Kunitake $\mathrm{R}$, Kaneko $\mathrm{Y}$, Hara N: The involvement of Fas-Fas ligand pathway in fibrosing lung diseases. Am J Respir Cell Mol Biol 1999, 20:53-60. 
17. Matute-Bello G, Winn RK, Jonas M, Chi EY, Martin TR, Liles WC: Fas (CD95) induces alveolar epithelial cell apoptosis in vivo: implications for acute pulmonary inflammation. Am J Pathol 200I, I 58: I53-|6I.

18. Gawlitta Debby, Oomens Cees WJ, Baaijens Frank PT, Bouten CVC: Evaluation of a continuous quantification method of apoptosis and necrosis in tissue cultures. Cytotechnology 2004, 46: $139-150$

19. Boffa DJ, Waka J, Thomas D, Suh S, Curran K, Sharma VK, Besada M, Muthukumar T, Yang H, Suthanthiran M, Manova K: Measurement of apoptosis of intact human islets by confocal optical sectioning and stereologic analysis of YO-PRO-I-stained islets. Transplantation 2005, 79:842-845.

20. Anto RJ, Mukhopadhyay A, Denning K, Aggarwal BB: Curcumin (diferuloylmethane) induces apoptosis through activation of caspase-8, BID cleavage and cytochrome c release: its suppression by ectopic expression of $\mathrm{Bcl}-2$ and $\mathrm{Bcl}-\mathbf{x l}$. Carcinogenesis 2002, 23: | 43-I50.

21. Ashkenazi A, Dixit VM: Apoptosis control by death and decoy receptors. Curr Opin Cell Biol 1999, I I:255-260.

22. Wajant $\mathrm{H}$ : The Fas signaling pathway: more than a paradigm. Science 2002, 296: I635-1636.

23. Kennedy SG, Kandel ES, Cross TK, Hay N: Akt/Protein kinase B inhibits cell death by preventing the release of cytochrome $C$ from mitochondria. Mol Cell Biol 1999, I9:5800-5810.

24. Okinaga T, Kasai H, Tsujisawa T, Nishihara T: Role of caspases in cleavage of lamin A/C and PARP during apoptosis in macrophages infected with a periodontopathic bacterium. J Med Microbiol 2007, 56:1399-1404.

25. Mashima T, Naito M, Tsuruo T: Caspase-mediated cleavage of cytoskeletal actin plays a positive role in the process of morphological apoptosis. Oncogene 1999, I 8:2423-2430.

26. Luo X, Budihardjo I, Zou H, Slaughter C, Wang X: Bid, a Bcl2 interacting protein, mediates cytochrome c release from mitochondria in response to activation of cell surface death receptors. Cell 1998, 94:48I-490.

27. Susin SA, Lorenzo HK, Zamzami N, Marzo I, Snow BE, Brothers GM Mangion J, Jacotot E, Costantini P, Loeffler M, et al.: Molecular characterization of mitochondrial apoptosis-inducing factor. Nature 1999, 397:441-446.

28. Susin SA, Daugas E, Ravagnan L, Samejima K, Zamzami N, Loeffler M, Costantini P, Ferri KF, Irinopoulou T, Prevost MC, et al.: Two distinct pathways leading to nuclear apoptosis. J Exp Med 2000 1 92:57|-580.

29. Garrido C, Galluzzi L, Brunet M, Puig PE, Didelot C, Kroemer G: Mechanisms of cytochrome $c$ release from mitochondria. Cell Death Differ 2006, I3:1423-1433.

30. Grossmann J, Mohr S, Lapentina EG, Fiocchi C, Levine AD: Sequential and rapid activation of select caspases during apoptosis of normal intestinal epithelial cells. Am J Physiol 1998, 274:GIII7-II24.

31. Piacenza L, Irigoin F, Alvarez MN, Peluffo G, Taylor MC, Kelly JM, Wilkinson SR, Radi R: Mitochondrial superoxide radicals mediate programmed cell death in Trypanosoma cruzi: cytoprotective action of mitochondrial iron superoxide dismutase overexpression. Biochem / 2007, 403:323-334.

32. Long TC, Tajuba J, Sama P, Saleh N, Swartz C, Parker J, Hester S, Lowry GV, Veronesi B: Nanosize titanium dioxide stimulates reactive oxygen species in brain microglia and damages neurons in vitro. Environ Health Perspect 2007, I I 5: I631-1637.

33. Goldberg M, Harel A, Gruenbaum Y: The nuclear lamina: molecular organization and interaction with chromatin. Crit Rev Eukaryot Gene Expr 1999, 9:285-293.

34. Broers JL, Bronnenberg NM, Kuijpers HJ, Schutte B, Hutchison C], Ramaekers FC: Partial cleavage of A-type lamins concurs with their total disintegration from the nuclear lamina during apoptosis. Eur J Cell Biol 2002, 81:677-69l.

35. Janmey PA: The cytoskeleton and cell signaling: component localization and mechanical coupling. Physiol Rev 1998 78:763-78I.

36. Gourlay CW, Ayscough KR: The actin cytoskeleton: a key regulator of apoptosis and ageing? Nat Rev Mol Cell Biol 2005, 6:583-589.

37. White SR, Williams P, Wojcik KR, Sun S, Hiemstra PS, Rabe KF, Dorscheid DR: Initiation of apoptosis by actin cytoskeletal derangement in human airway epithelial cells. Am J Respir Cell Mol Biol 200I, 24:282-294.

38. Yacoub A, Park MA, Hanna D, Hong Y, Mitchell C, Pandya AP, Harada $\mathrm{H}$, Powis G, Chen CS, Koumenis C, et al.: OSU-030I 2 promotes caspase-independent but PERK-, cathepsin B-, BID-, and AIF-dependent killing of transformed cells. Mol Pharmacol 2006, 70:589-603.

39. Landshamer S, Hoehn M, Barth N, Duvezin-Caubet S, Schwake G, Tobaben S, Kazhdan I, Becattini B, Zahler S, Vollmar A, et al.: Bidinduced release of AIF from mitochondria causes immediate neuronal cell death. Cell Death Differ 2008.

40. Cande C, Cecconi F, Dessen P, Kroemer G: Apoptosis-inducing factor (AIF): key to the conserved caspase-independent pathways of cell death? J Cell Sci 2002, I I 5:4727-4734.

41. Otera H, Ohsakaya S, Nagaura Z, Ishihara N, Mihara K: Export of mitochondrial AIF in response to proapoptotic stimuli depends on processing at the intermembrane space. Embo 2005, 24: $1375-1386$.
Publish with Biomed Central and every scientist can read your work free of charge

"BioMed Central will be the most significant development for disseminating the results of biomedical research in our lifetime. "

Sir Paul Nurse, Cancer Research UK

Your research papers will be:

- available free of charge to the entire biomedical community

- peer reviewed and published immediately upon acceptance

- cited in PubMed and archived on PubMed Central

- yours - you keep the copyright 